\title{
A Review on Efficient Identification of Posture Alterations Through the Analysis of the Footprint and Artificial Vision Technologies
}

\author{
TAHA AHMADI, HERNÁNDEZ CRISTIAN, CUBILLOS NEIL \\ Universidad de Cundinamarca, COLOMBIA
}

\begin{abstract}
This article presents a review of the most relevant manual techniques and technologies developed from the field of artificial vision aimed at identifying biomechanical alterations. The purpose is to describe the most important aspects of each technology, focused on the description of each of its stages and experimental results, which suggest the integration of mobile devices with artificial vision techniques, in addition to the different computer programs used for such end. Finally, the results showed that the identification of the crook index for alterations in posture turns out to be a technique currently used by most specialists. The great challenge is to develop portable devices through mobile applications that allow the detection of the corvo index and the barometric analysis, as well as for other types of applications that depend on visual analysis by experts.
\end{abstract}

Key Words: Plantar Footprint, Hernández Corvo Index, Cavo Foot, Flat Foot, Normal Foot, Podoscope

Received: July 26, 2020. Revised: December 19, 2020. Accepted: March 4, 2021. Published: March 9, 2021.

\section{Introduction}

The analysis and diagnosis of the plantar footprint is a process that has been of great importance in the prevention and correction of postural problems of a person or individual [1]. Currently there are different methods of obtaining and classifying the foot from empirical and rapid methods such as visual inspection, to more accurate methods such as the Hernández Corvo method. Each of these procedures seeks to classify the plantar footprint into three possible groups, pes cavus, normal and flat, in order to proceed with a special treatment according to the results obtained, such as therapies, change of routines and use of special templates.

The analysis of the plantar footprint is examined in any person to identify possible alterations in posture, however, in the literature it was evidenced that studies focus on specific communities that most suffer from postural problems or are of greater importance such as children, people with diabetes and athletes; In the latter, it is necessary to monitor the progress and trend of the footprint gradually, due to the increase in alterations in the foot that athletes present due to their daily activity.

At present, the Hernández Corvo index has proven to be one of the most accurate methods, which is why it is one of the most used; Different procedures and devices have been developed for this purpose, these devices range from the rustic, manual and delayed to the automated and computerized ones, in any of these their operation is based mainly on the impression of the plantar footprint on some surface, where later it is they make the corresponding strokes to find areas on the foot and thus determine their index and classification of the footprint. Technologically, the process is carried out with the use of platforms called podoscopes that highlight the footprint on a glass surface that is later analyzed by the doctor or captured with a camera or scanner to be processed by software.

In this review of the state of the art, the most recent advances in the identification of the corvo index, identification of alterations in posture, among others, are exposed, emphasizing novel scientific documents 
on the subject. The results found show the importance of developing systems on mobile devices that can support the analysis of the plantar footprint objectively and without inter- and intra-laboratory measurements. These challenges are faced with the development of computational tools, based on digital image processing to achieve a better identification of alterations in posture, in order for the expert to make a timely diagnosis.

\section{Background}

The following bibliographic review will be divided into two parts; one from the field of statistical and demographic studies of the footprint in different populations and a second part will address the field of technological development of devices for the analysis and classification of the footprint.

\section{- Statistical and demographic studies}

Multiple studies carried out in different world populations about foot pathologies have revealed important advances in the technique with satisfactory and novel results, such is the case of the study carried out by Australian researchers in [2], which consisted of an exhaustive review and verification Of techniques for the correction of flat feet or cavus in common people, the people were randomly selected, later they underwent X-rays and the Hernández corvo analysis, it was evidenced that it is possible to reliably detect abnormalities such as flat feet. Thanks to the information that is corroborated with the use of the two techniques, a low error rate was obtained, but concluding that research is lacking to obtain information with radiological methods. Finally, the importance and help of radiological images in foot analysis is highlighted since, despite being little studied, the results of radiographic images extend the analysis of anomalies such as plantagias.

The study and analysis of the plantar footprint carried out in a community in [2] with very similar activities or conditions, yields specialized or additional information that allows decision-making regarding said activity, such is the case of the podoscopic study carried out in women with three different routines (sedentary, hockey player and soccer player), which are analyzed based on the Hernández corvo method and the heel angle in order to observe postural aggravations with the practice of these sports.

The Hernández corvo method is developed after the capture of the plantar footprint, in this footprint strategic lines are made, such as those observed in figure 1 , which allow the calculation of said index.

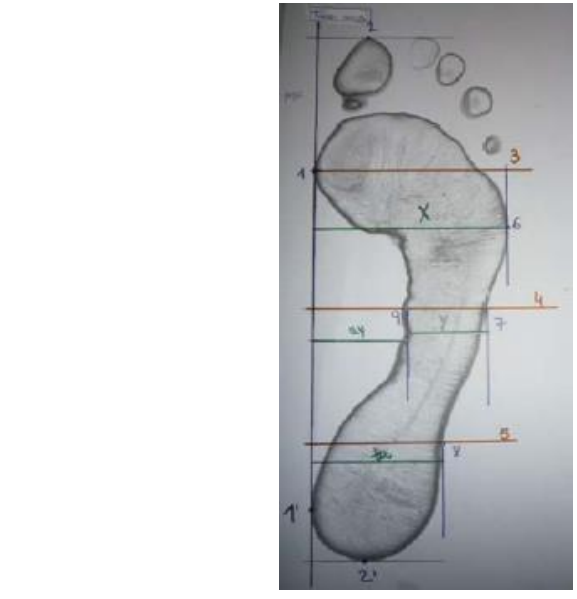

Figure 1- Plantar footprint evaluation, corvo method Hernandez, Taken from [3]

From the previous figure we take a distance ' $\mathrm{x}$ ' and a distance ' $y$ ', which are involved in the following equation.

According to the percentage finally obtained, it is analyzed and classified according to the type of foot of the person where $0-34 \%$ is known as Flatfoot; 35 39\%: Flat / normal foot; 40-54\%: Normal foot; $55-$ 59\%: Normal / cavus foot; $60-74 \%$ : pes cavus; $75-$ 84\%: strong cavus foot; $85-100 \%$ : Extreme cavus foot.

The angle that the heel forms with the rest of the leg is a technique that also makes it possible to classify postural abnormalities. 


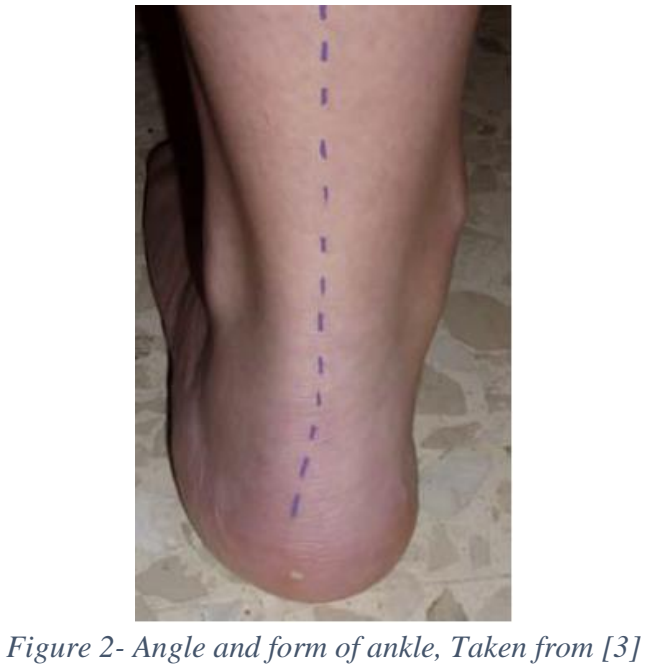

In taking this factor, it is emphasized that a normal foot with normal posture should not exceed 7 degrees of inclination, based on the lateral axis of the body, as evidenced in figure 2 .

After processing and tabulating the data obtained, it is concluded that the women with the greatest tendency to foot problems are soccer players, but they are not alarming or significant data, since they are due to different techniques used that do not have serious problems, another point to be analyzed is the effectiveness of the Hernández Corvo method, since it provides telling information

Corroborating the foregoing, Spanish researchers in [3] carry out a comparison of multiple methods for foot analysis, finding that the method with the highest efficiency index is also that of Hernández corvo, above the other poorly documented and not highly recommended methods.

In general, foot problems are known as plantagias in [4], more precisely in the foot plate, these conditions are excessively painful and affect, among other things, the posture of the person, which leads to joint problems that deteriorate over time, for this reason it is very important to prevent these anomalies, through the use of bandages or performing a plantar fasciotomy. or when it comes to plantagias in the middle area of the sole of the foot, corrective templates are used.

Other groups in which the foot analysis is a necessity are children, obese and diabetic people, since they are more vulnerable to presenting this type of problems, which causes apart from social problems, also posture difficulties, weight distribution, wear on the knees, among others.

Countless studies have been carried out in these groups of people, having as a common point, aggravating factors such as overweight, nutritional imbalances, incorrect use of footwear, among others. In the case of overweight people, a study carried out in Mexico in [5] leaves an impressive percentage of almost $13 \%$ of people with flat feet, a very significant figure considering that those evaluated were entirely people with a mass index high.

Another point to clarify are the plantar problems and their relationship with the type of footwear, since the foot can be deformed by the improper use of footwear.

The shoe that is traditionally questioned not only for generating flat feet but also an infinity of bodily problems is the heel type, this has inspired the study of Brazilian researchers in [6] [7], but to the astonishment of many, they conclude that shoes with platform or heel do not influence or affect the foot, compared to a possible flat foot.

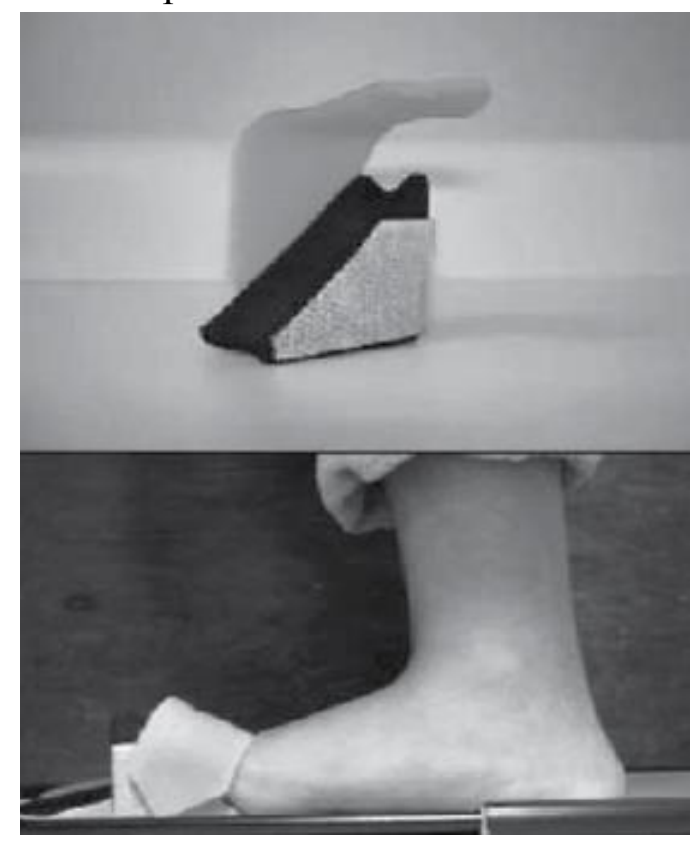

Figure 3-Jack method, taken from [4].

Children are very susceptible to suffering from plantar anomalies since they are in constant development, for this reason it is important to detect and prevent the appearance of flat feet, for this task 
in Brazil in [8] the way to have more truthful results was devised, With minimal spending of money, they finally achieved this by implementing Jack's technique, which as seen in figure 3 , consists of placing a platform (orthosis) on the thumb of the foot, and making an impression of it, after Remove the platform and observe the changes in the footprint, with this it is possible to observe more accurately and with greater resolution the foot problems, achieving normalize the results when using the orthosis, the results were analyzed by implementing the Volpon and Valentini methods.

At the national level, the study and application of the footprint has been of great help in the sports area, such is the case of the research carried out in the Cali university in [9] where they implement a foot analysis of 250 Colombian athletes implementing the method de Hernández corvo in the XVIII national games, processing the information digitally, finding that the athletes with the most frequency in flat feet and cavities are the athletes and swimmers, with a more direct relationship in swimmers.

\section{- Technological development}

The constant increase and boom in the development of software and image processing has allowed the development of different processes oriented towards different areas such as the medical one. Currently, the development of new technologies and algorithms of greater efficiency and speed is of great importance; It is worth highlighting the studies carried out by the author Geert Litjens together with his colleagues in the Netherlands in 2017 [10] where they managed to conclude that the use of convolutional neural networks has quickly become a methodology of choice to analyze medical images achieving better results compared to other techniques; These authors were based on the study of 308 articles all oriented to medical applications such as analysis of neuronal, retinal, pulmonary, breast, cardiac, abdominal and musculoskeletal pathologies.

One of the most relevant aspects when analyzing images through the use of software is the processing speed, so it is very important to evaluate the physical characteristics of the implemented devices and make a comparison with other technologies from the point of view of Hardware offering us better performance, such as the use of FPGA vs a heterogeneous multicore processor (CELL), where FPGA technology achieved a speed of 2.5 times higher than CELL technology when processing the iris image. of a person [11]. As shown in figure 4, part of the cortex of the iris was extracted to be subsequently processed with the FPGA.

From another point of view, but taking as a reference the argument presented above, the use and use of the GPU of the different devices has allowed obtaining higher speeds of processing images or high-resolution video in real time [12]; This being a still underdeveloped technology, but with great expectations, due to the qualities it offers, it is worth highlighting a study carried out on the use of GPUs in X-ray computed tomography applications, achieving the reconstruction of high quality images from the projections taken. at the time of the exam application; Once the corresponding algorithms were carried out using GPUs, they were able to observe high efficiency and, as the main quality, a notable cost reduction compared to current equipment for this purpose [13].

During the bibliographic review carried out, it was observed that the development of devices oriented to the analysis of the plantar footprint has been a boom in recent years due to the importance of its analysis and the need to change from manual and empirical to automatic processes. The development of these devices has been classified into two groups: Podoscopes (Oriented to the study of the shape of the plantar footprint) and Bar-podoscopes (Oriented to the pressure exerted on the different parts of the footprint).

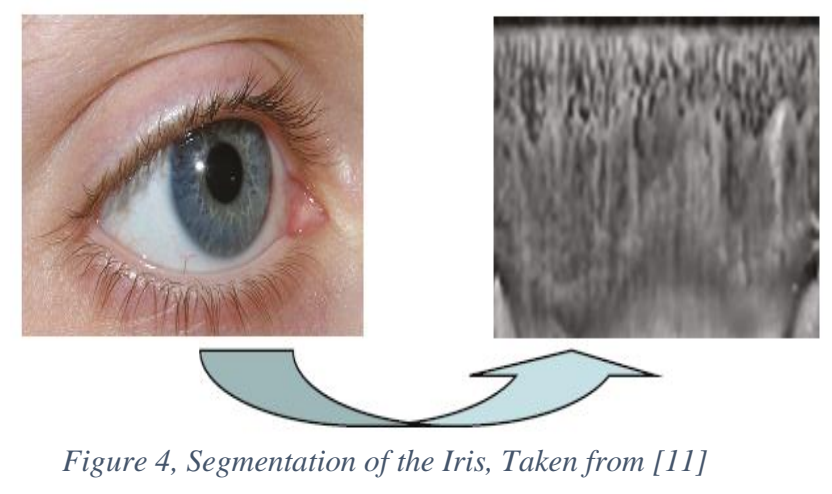




\section{- Development of podoscopes}

The measurement of the plantar footprint is essential to know the distribution of forces on the sole of the foot. These values are important for the diagnosis and treatment of different pathologies such as diabetic ulcers on the sole of the foot and the presence of deformities in the lower extremities, among others [14].

The basic principle of operation of a podoscope is based on the use of a translucent surface (generally glass), which allows it to act as a transducer to later be taken the image with the help of a camera. This operation is shown in figure 5; in these devices, good lighting of the scene is of great importance, which can be used from different points or techniques; for example applying structured lighting that turns out to be efficient to characterize the surface of opaque objects, achieving with this quality to characterize the morphology of the footprint [15].

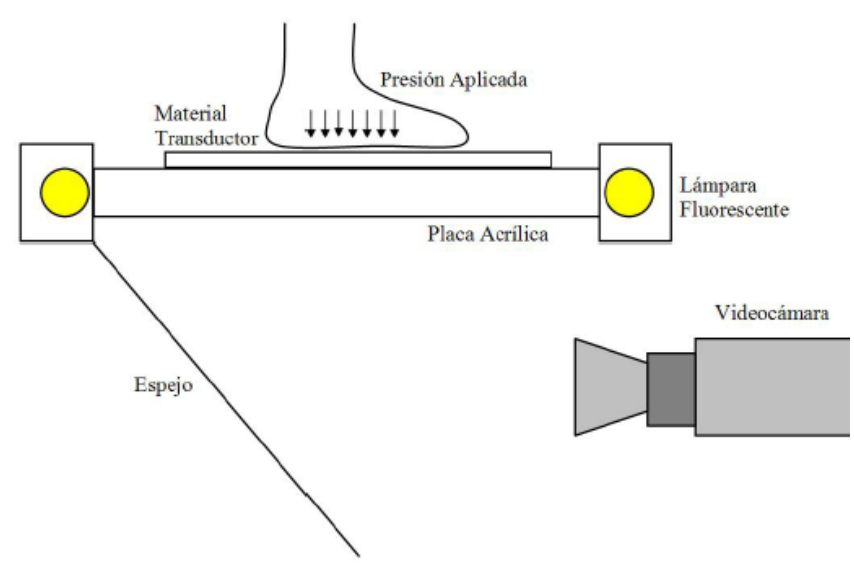

Figure 5, Basic Operation Podoscope, Taken from [14]

From the point of image processing as shown in figure 6 , once the image has been taken, a series of steps is carried out that include applying filters, segmentation, contrast adjustment, edge detection, etc. The application of one or the other will vary depending on the system designer and the quality of the captured image; Most of these processes are based on statistical techniques such as the use of the Poisson distribution to perform an image segmentation [16] [17]. With these techniques, an improvement in the captured image is sought, in order to later obtain better results through analysis and processing.

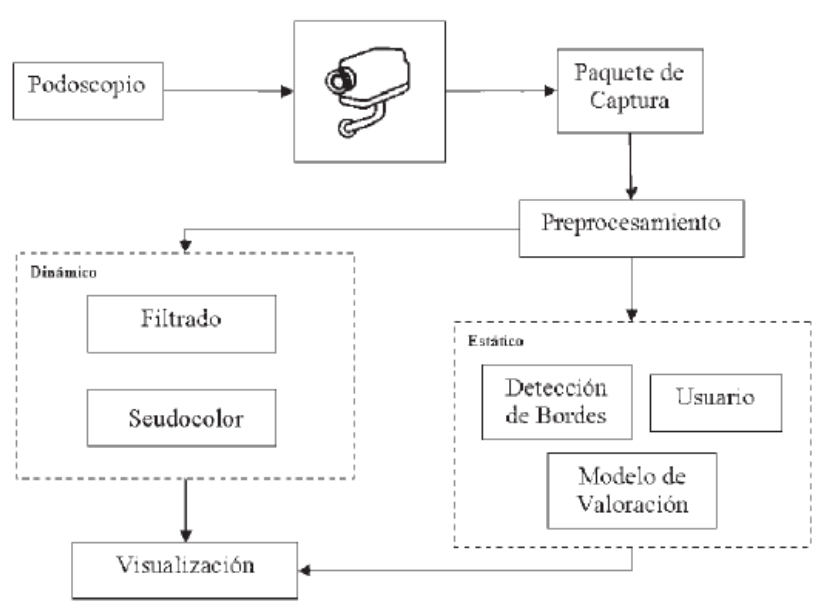

Figure 6, Basic Methodology of a Podoscope, Taken from [14]

The creation and use of a podoscope allows an analysis of the plantar footprint by analyzing its shape and pressure area with the surface, thus achieving a classification of it; The most famous and currently used method is the Hernández Corvo plantar footprint classification method, which consists of obtaining different areas within the footprint and thus obtaining an index through a specific equation as shown in figure 7 and 8 , where the different lines that must be made to later classify the type of foot are shown with the equation proposed in figure 8 .

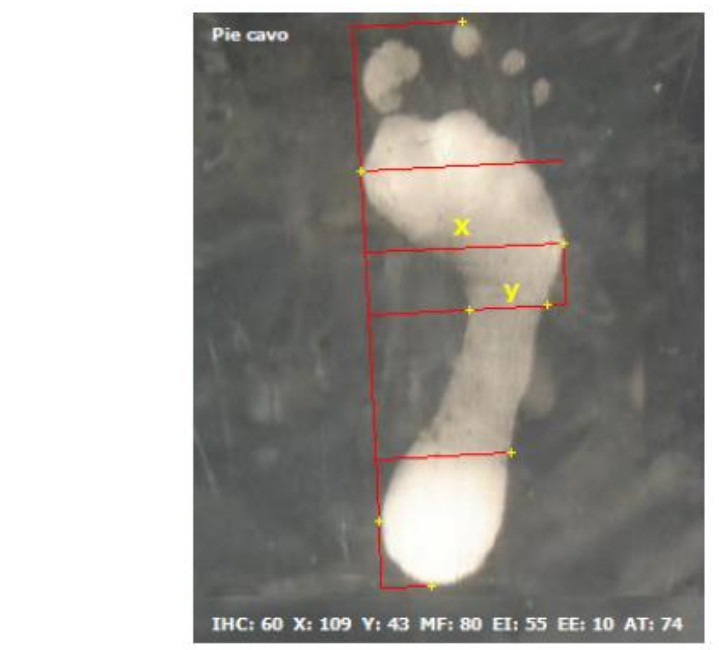

Figure 7, Areas within the Footprint According to Hernandez Corvo, Taken from [14]

$$
I C=\frac{X-Y}{X}
$$

\begin{tabular}{|l|l|}
\hline $0-34 \%$ & Flat foot \\
\hline $35-39 \%$ & Flat-normal foot \\
\hline $40-45 \%$ & Normal foot \\
\hline
\end{tabular}




\begin{tabular}{|l|l|}
\hline $55-59 \%$ & Normal- cavus foot \\
\hline $60-74 \%$ & Cavus foot \\
\hline $75-84 \%$ & Strong cavus foot \\
\hline $85-100 \%$ & Extreme cavus foot \\
\hline \multicolumn{2}{|c|}{ Figure 8, Hernandez Corvo equation, Taken from [14] }
\end{tabular}

It is very popular to find podoscopes with good performance on the market, but at too high a price, so much research has been directed to the design and manufacture of low-priced podoscopes, but with reliable results.

A group of students from the Polytechnic University of Sinaloa in Mexico [18] decided to create a lowcost podoscope, achieving good results. In his article, the main problem is raised when analyzing the footprint since, because a professional podoscope is so expensive, most doctors perform a manual analysis using ink and a sheet of paper like shown in figure 9 .
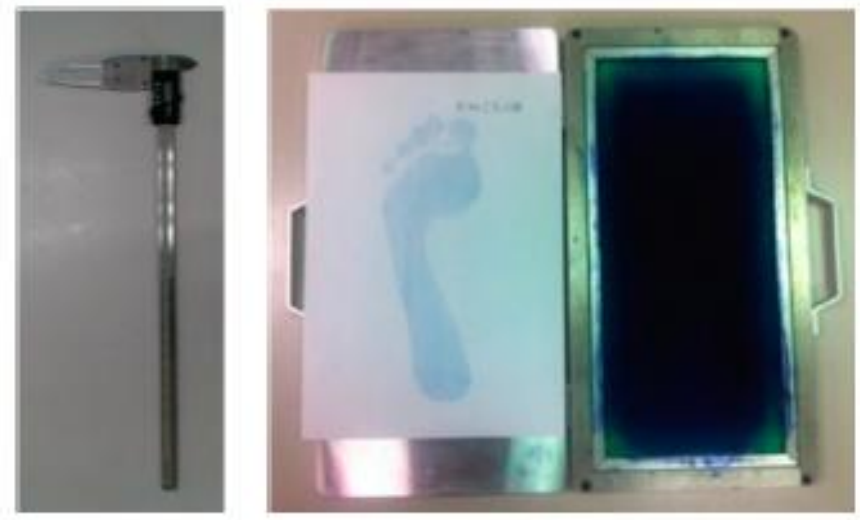

Figure 9, Usual Process for the Plant Footprint Analysis, Taken from [18]

The solution developed by this group of researchers lay in the construction of a platform that allows the capture of the plantar footprint and with the help of a raspberry pi3 to obtain a processing of it, the methodology used is shown in figure 10 .
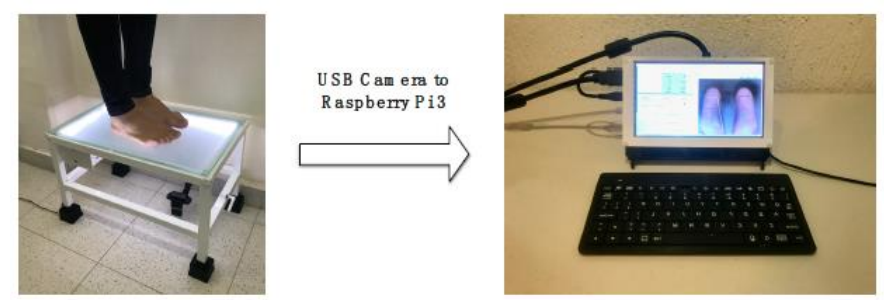

Figure 10, Footprint Processing with Raspberry Pi3, Taken from [18]
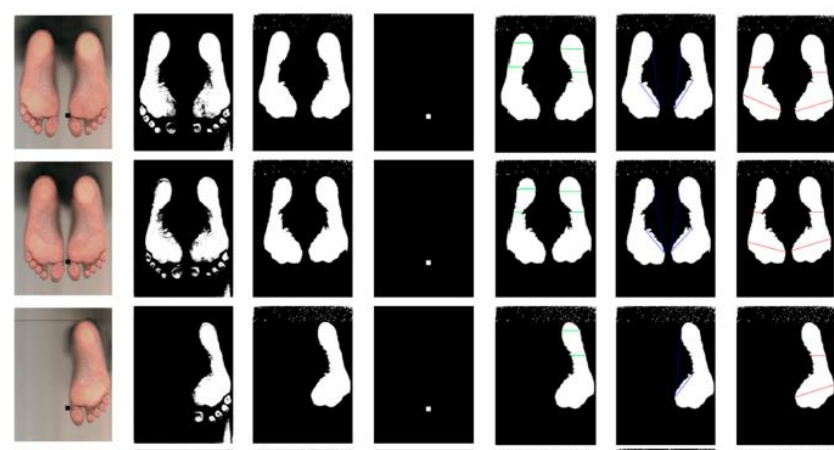

Oec
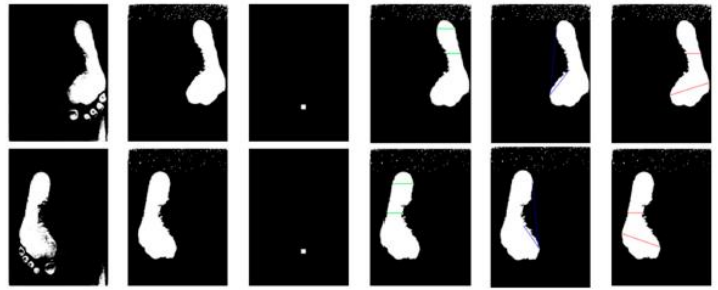

Figure 11, Results Obtained, Taken from [18]

Figure 11 shows the results obtained and the corresponding segmentation stages implemented in the system; Similarly, it is shown that an extraction of each foot was carried out for its subsequent analysis and the use of a static table of a specific area as a guide to determine areas within the plantar footprint.

Another clear example of the need for the construction of a low-cost podoscope was presented by a group of researchers in Ecuador [19] achieving a capture of the plantar footprint totally different from the previous ones, thus achieving better results due to a simple processing of the image through the development of a desktop-oriented application capable of determining the $\mathrm{X}$ and $\mathrm{Y}$ dimensions of each foot, the percentage of crook in each limb and its classification as shown in figures 12 and 13, after observing the results obtained, it was evident that the same type of foot is not necessarily obtained in each limb.

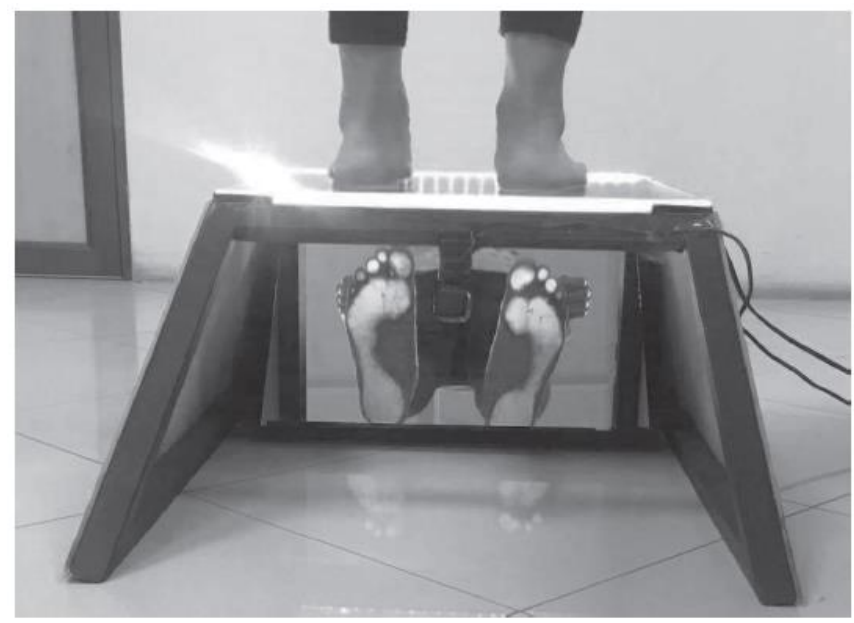

Figure 12, Implemented podoscope, Taken from [20] 


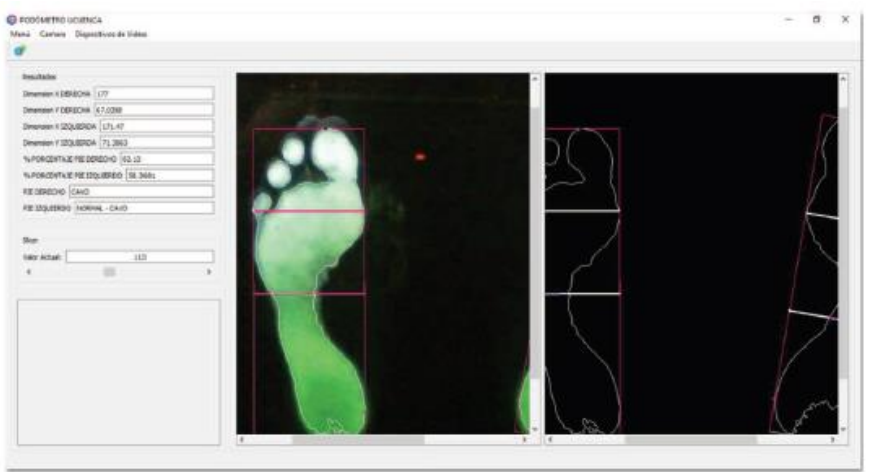

Figure 13, Results Obtained, Taken from [20]

Addressing a broader point of view, a group of authors from the Universidade José do Rosário Vellano in Brazil [21] presents a study in which not only the shape of the footprint is studied, but also the importance of studying the lower limbs (foot, heel, ankle, tibia and fibula) when preventing and correcting biomechanical problems of an individual. The methodology used consisted in the detection of different markers located in different parts of the foot, heel, ankle, tibia and fibula to later determine different angles for a later diagnosis as shown in Figure 14.

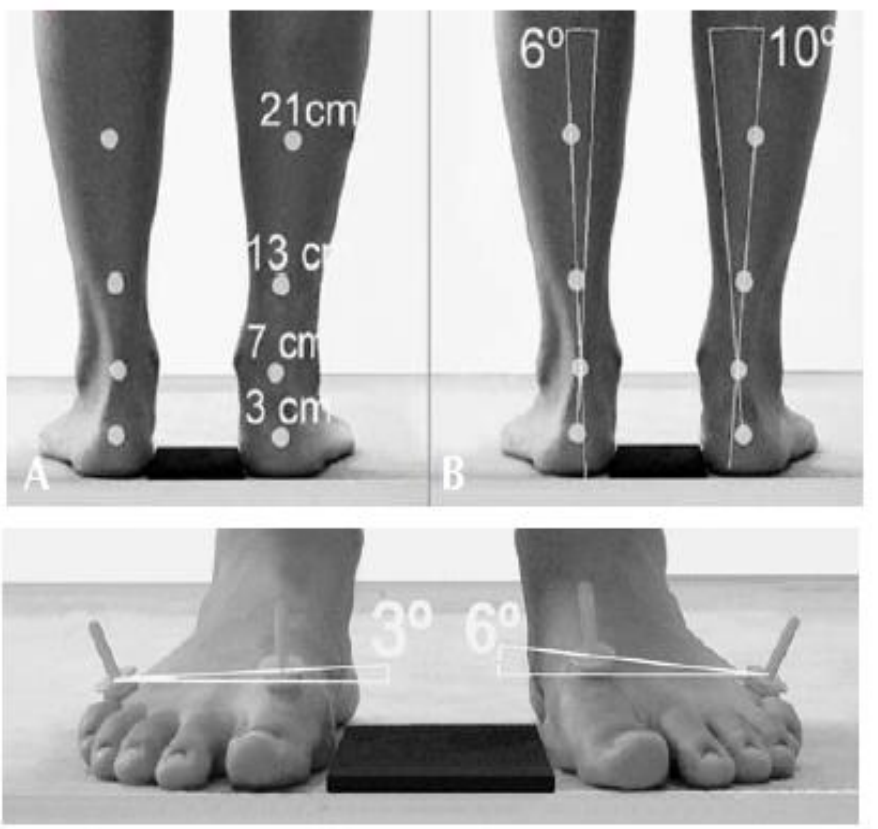

Figure 14, Biomechanical Analysis of the Lower Limbs, Taken from [21]

\section{- Development of Baropodoscopes}

The main disadvantage of podoscopes is their limitation to only the classification of the plantar footprint according to its shape and area, but it does not take into account the pressures exerted in the different areas of the human foot.
A group of students from Ecuador [19], within their research, decided to build a template as shown in figure 15, which allows the capture of foot pressure when walking with the help of an Arduino Uno for data collection and use of strain gauges for measurement.

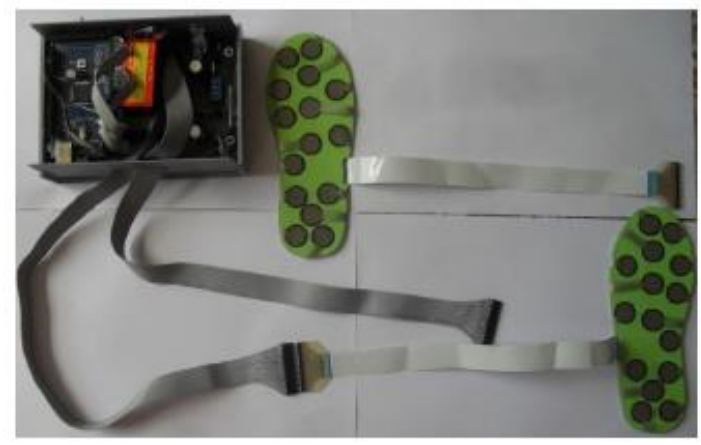

Figure 15, Bar-podoscope, Taken from [19]

By carrying out a transduction of the pressures obtained, the authors were able to obtain an image of the plantar footprint, but due to the use of so few sensors, it was not possible to obtain an image of good resolution as shown in Figure 16.

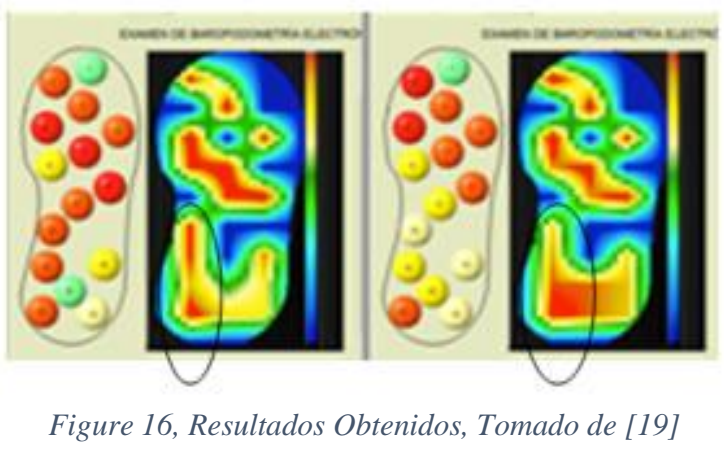

In the same way, different authors in other investigations have proposed the development of similar devices, obtaining results with the same resolution problems. Figures 17, 18 and 19 show the developed device that likewise consists of a data acquisition system together with pressure sensors. Figure 18 shows the different pressure points registered and the values obtained by the transducers or sensors. 


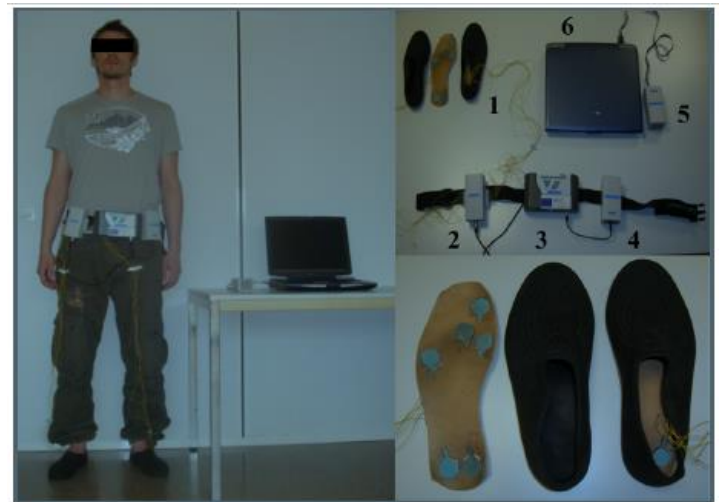

Figure 17, Bar-podoscope, Taken from [22]

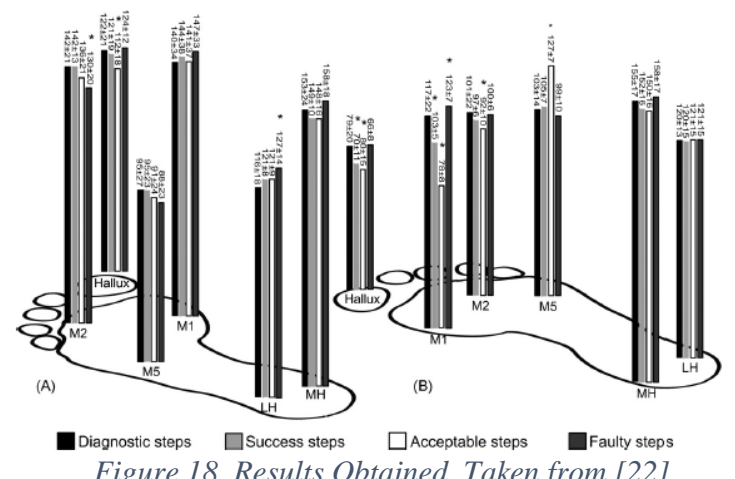

Figure 18, Results Obtained, Taken from [22] (a)

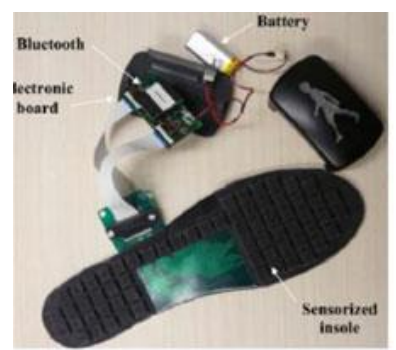

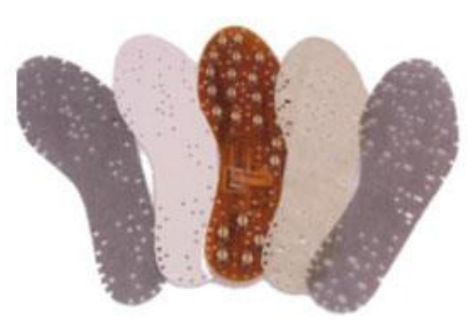

(b)
Figure 19, Bar-podoscope, Taken from [23]

On the other hand, in the thesis presented by a couple of students from the Universidad Distrital de Colombia in 2016 [24], the manufacture of a podoscope together with a baropodoscope is exposed, thus achieving an interpolation of results and arriving at a plantar analysis of Greater precision. Figures 20, 21 and 22 show the device developed and its operation, which consists of acquiring a first measurement with the barpodoscope and subsequently taking the plantar footprint with the podoscope.
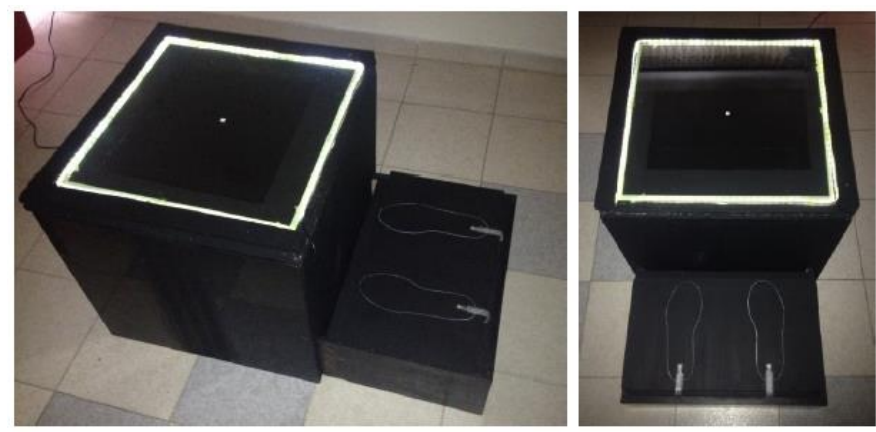

Figure 20, Podoscope together with bar-podoscope, Taken from [24]
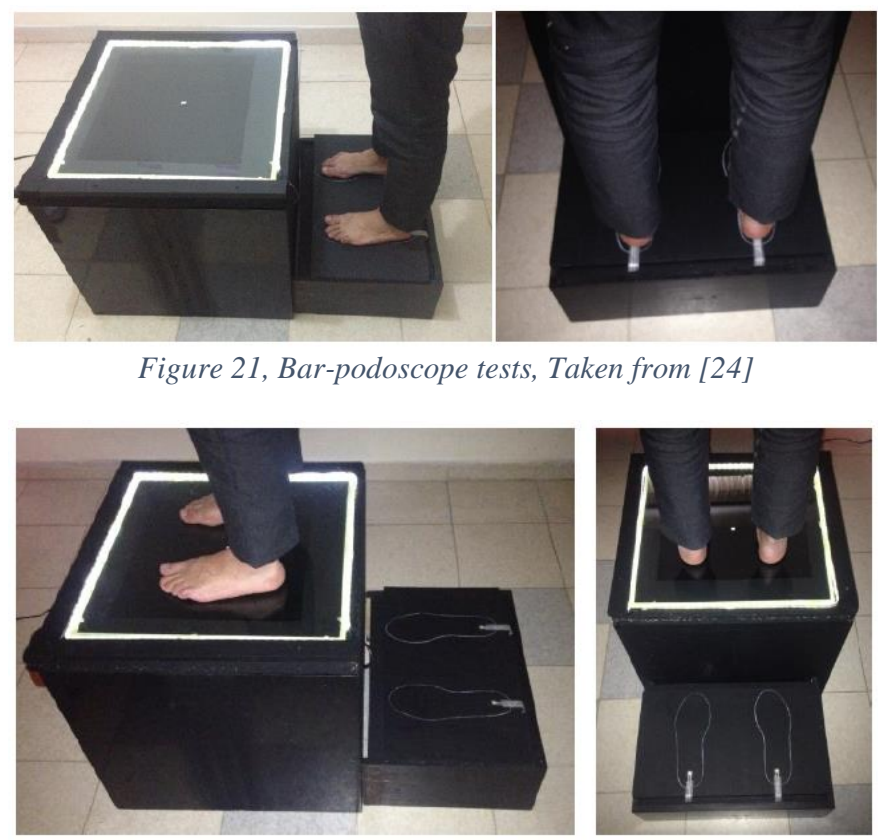

Figure 22, Podoscope Test, Taken from [24]

Once the corresponding measurements and image capture have been made, and with the help of Matlab and the development of a guide, the correlations of the podoscope and bar-podoscope are carried out as shown in figure 23, obtaining an image of excellent quality for analysis and determination of the corvo index.

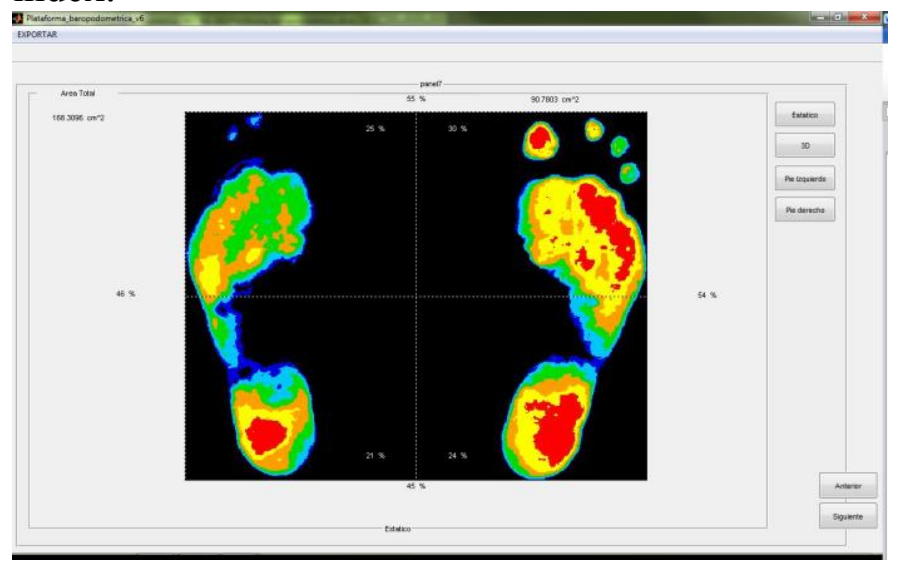

Figure 23, Results Obtained, Taken from [24] 
Thanks to the use of a bar-podoscope, it is possible to construct a 3D image with the pressures exerted on each part of the plantar footprint as shown in figure 24 .

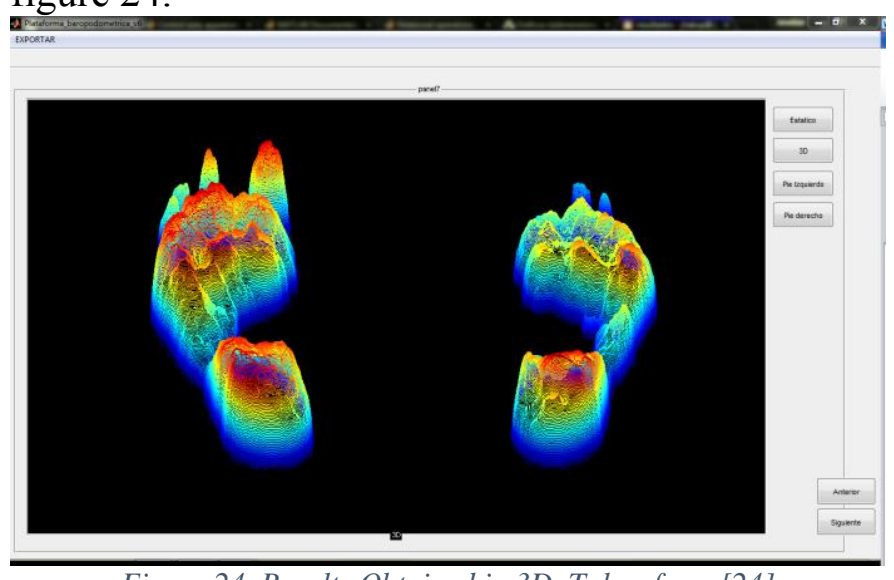

Figure 24, Results Obtained in 3D, Taken from [24]

\section{Conclusions}

The analysis of the plantar footprint is a procedure of great importance because it is possible with it to correct future hip or knee problems, applying the different treatments with the result obtained.

In athletes, a constant analysis of the plantar footprint is necessary because, depending on the physical activity practiced, there may be alterations in the foot causing poor sports performance; In addition, if the different treatments are applied properly, greater efficiency can be achieved in your sports activities.

Current plantar footprint analysis techniques, some tend to be empirical, taking too much time to analyze, while processes that are carried out automatically with software and hardware tend to be too expensive.

\section{Recomendations}

At present, the study of the footprint has been oriented towards a certain type of population, especially children and athletes; it is necessary to carry out studies oriented towards another type of population, thus obtaining statistical data on the affectations of ordinary individuals.

The development and construction of low-cost devices for the analysis of the plantar footprint is possible, thus achieving the possibility of offering a diagnosis to a larger population.

\section{References}

[1] J. C. C. Pérez, «http://www.efdeportes.com,» [En línea]. Available:

http://www.efdeportes.com/efd140/importancia-delanalisis-de-la-huella-plantar.htm.

[2] L. S. M.-L. C. Z. y. L. D. Berdejo-del-Fresno, «ALTERACIONES DE LA HUELLA PLANTAR EN FUNCIÓN DE LA ACTIVIDAD FÍSICA REALIZADA,» Rev.int.med.cienc.act.fis.deporte, vol. 13, p. 21, 2011.

[3] A. J. L. S. M. L. Z. S. E. J. M.-L. Silvia Lara Diéguez, «Análisis de los diferentes métodos de evaluación de la huella plantar,» RETOS. Nuevas Tendencias en Educación Física, Deporte y Recreación,, vol. 19, p. 6, 2011.

[4] E. F. ORTIZ, «Plantagias Medias,»Rev Asoc Argent Ortop Traumatol, p. 28, 2008.

[5] A. G. R. M. A. R. A. y. P. P.-R. Héctor Iván SaldívarCerón, «Obesidad infantil: factor de riesgo para desarrollar pie,» Elsevier, p. 6, 2015.

[6] T. H. S. F. V. C. A. Lígia L. Cisneros, «Inter- and intraexaminer reliability of footprint pattern analysis obtained from diabetics using the Harris Mat,» Revista Brasileira de Fisioterapia, p. 6, 2010.

[7] I. C. N. S. S. M. A. J. Patrícia A. O. Pezzan, «Foot posture and classification of the plantar arch among adolescent wearers and non-wearers of high-heeled shoes,» Revista Brasileira de Fisioterapia, p. 7, 2009.

[8] E. S. O. A. L. N. S. R. F. C. B. E. T. D. José Antonio Pinto, «FOOTPRINT STUDY IN CHILDREN DURING THE JACK TEST,» Acta Ortop Bras., p. 4, 2011.

[9] J. M. F. A. J. J. N. P. E. A. V. E. D. V. V. B. L. J. H. Lessby Gómez Salazar, «Características de la huella plantar en deportistas colombianos,» Unilibre Cali, p. 10, 2010.

[10] L. Geert, K. Thijs, E. B. Babak, A. S. Arnaud Arindra, C. Francesco, G. Mohsen, v. d. L. Jeroen A.W.M., v. G. Bram y S. Clara I., «A survey on deep learning in medical image analysis,»ElSevier, p. 29, 2017.

[11] R. Ryan N., N. Hau, B. Randy P. y I. Robert W., «Comparing an FPGA to a Cell for an Image Processing Application,» SpringerLink, p. 7, 2010.

[12] C. Jiawen, P. Sylvain y F. Durand, «Real-time EdgeAware Image Processing with the Bilateral Grid,» ACM SIGGRAPH conference proceedings, p. 9, 2007.

[13] F. Liubov A., V. Vicent, M. Patricia, R. Francisco y V. Gumersindo, «ParallelCTimagereconstructionbasedonGPUs,» ELSEVIER, p. 4, 2014.

[14] C. A. Díaz, A. Torres y J. I. Ramirez, «Descripción de un sistema para la medición de las presiones plantares por medio del procesamiento de imagenes - Fase 1,» Scielo, p. 14, 2006.

[15] A. M. Yeras, «Iluminación Estructurada: una Herramienta para el Estudio Morfológico del Pie,» SpringerLink, p. 4, 2011. 
[16] C. Qiang y H. Chuanjiang, «Variational segmentation model for images with intensity inhomogeneity and Poisson noise,» SpringerLink, p. 11, 2013.

[17] B. F. J., M. D., B. V. y P. J., «Digital image processing techniques applied to pressure analysis and morphological features extraction in footprints,» IOPscience, p. 11, 2016.

[18] M. R. Rodolfo, R. Tomas, S. H. Juan, C. A. Ivan, C. M. Luis, D. G. Carlos y F. J. Arturo, «Low ComputationalCost Footprint Deformities Diagnosis Sensor through Angles, Dimensions Analysis and Image Processing Techniques,» Sensors, p. 17, 2017.

[19] P. L. F., G. A., M. E. y B. D. S., «A Low Cost Baropodometric System for Children's Postural and Gait Analysis,»IEEE, p. 4, 2016.

[20] M. Ruben, Z. P. Ana L. y M. Villie, «Footprint Analysis Using a Low Cost Photo-Podoscope,» IEEE, p. 6, 2017.

[21] S. Francis Trombini, R. Ana Paula, L. Denise Hollanda y M. R. Vanessa Vilela, «Correlações entre as estruturas dos membros inferiores,» Scielo, p. 6, 2009.

[22] D. Aurélien, T. André y M. Pierre, «Baropodometric information return device for foot unloading,» ElSevier, p. 7, 2009.

[23] R. B. Julian Andres y C. C. Silvia Liliana, «A Review in Detection and Monitoring Gait Disorders Using In-Shoe Plantar Measurement Systems,» IEEE, p. 11, 2017.

[24] P. T. JONATTAN STEVE y R. P. ESNEYDER ALFONSO, DISEÑO E IMPLEMENTACIÓN DE UNA PLATAFORMA BAROPODOMÉTRICA PARA MEDICIÓN DE PUNTOS DE PRESIÓN PLANTAR EN BIPEDESTACIÓN CON VISUALIZACIÓN EN ORDENADOR A PARTIR DE UN SISTEMA DE ADQUISICIÓN, Bogota: UNIVERSIDAD DISTRITAL FRANCISCO JOSÉ DE CALDAS, 2016.

[25] F. Carlos, M. Ximena, L. Humberto, L. Steven y H. Sebastian, «SISTEMA DE EXTRACCIÓN AUTOMÁTICA DE PARAMÉTROS MORFOLÓGICOS DE LA HUELLA PLANTAR MEDIANTE TÉCNICAS DE VISIÓN POR COMPUTADOR EN UN SISTEMA EMBEBIDO,»
Revista Colombiana de Tecnologías de Avanzada, p. 7, 2013.

[26] M. Rubén, B. Sebastián, Z. P. Ana L. y M. Villie, «Aplicación de Técnicas de Visión por Computador para Apoyo al Diagnóstico de la Pisada: Fotopodómetro Digital,»Researchgate, p. 10, 2016.

[27] K. Prachi S. y K. Vinayak B., «Human Footprint Classification using Image parameters,»IEEE, p. 5, 2015.

[28] F. B. Carlos Diego, M. Ximena y L. C. Humberto, «Determinación semiautomática de parámetros morfológicos de la huella plantar mediante el procesamiento digital de imágenes,» Icesiaotronivel, p. 19, 2013.

[29] F. C. D. y L. H., «A Real-Time Multispectral Computer Vision System for Morpho-Thermal Analysis of Footprint Plantar,» IEEE, p. 7, 2015.

[30] L. Navaporn, C. Kittipol, T. Suradej y H. Cherdpong, «Smart Digital Podoscope for Foot Deformity Assessment,»IEEE, p. 5, 2014.

[31] G. Leonardo G., S. Reginato, A. d. S. Mauren y R. G. Humberto, «Biofeedback baropodometry training evaluation: A study with children with equinus foot deformity,»IEEE, p. 4, 2013.

[32] H. B. M. ,. K. B. L. George S Murley, «A protocol for classifying normal- and flat-arched foot posture for research studies using clinical and radiographic measurements,» BioMed Central, p. 12, 2009.

[33] L. O. M. R. I, L. M. F. L. II, M. M. GonzálezIII, S. B. G. IV, J. E. L. V. V, P. F. PlanesIV y M. J. H. IV, «Triple artrodesis en el tratamiento de las deformidades podálicas en la edad pediátrica,» scielo, p. 23, 2011.

[34] A. J. L. S. M. L. Z. S. E. J. M.-L. Silvia Lara Diéguez, «Análisis de los diferentes métodos de evaluación de la huella plantar,» Retos. Nuevas tendencias en Educación Física, Deporte y Recreación, no 19, p. 6, 2011.

[35] S. P.-F. T. S.-P. B. L.-C. S. P.-D. V. G.-G. Cristina Gonzalez-Martin, «Variabilidad entre el ángulo de Clarke y el índice de Chippaux- Smirak para el diagnóstico de pie plano,» Colombia Medica, vol. 48, n 1, p. 7, 2017.

\section{Creative Commons Attribution License 4.0 (Attribution 4.0 International, CC BY 4.0)}

This article is published under the terms of the Creative Commons Attribution License 4.0

https://creativecommons.org/licenses/by/4.0/deed.en_US 